\title{
Paternal uniparental disomy of chromosome 20
}

INSERM

\section{Source}

INSERM. (1999). Orphanet: an online rare disease and orphan drug data base. Paternal uniparental disomy of chromosome 20. ORPHA:96194

Paternal uniparental disomy of chromosome 20 is a very rare chromosomal anomaly in which both copies of chromosome 20 are inherited from the father. The main features described are high birth weight and/or early-onset obesity, relative macrocephaly, and tall stature. Most patients were ascertained during sporadic pseudohypoparathyroidism type $1 \mathrm{~b}$ (see this term) testing and have UPD involving variable segments of the long arm of chromosome 20. 